\title{
Forest cover enhances natural enemy diversity and biological control services in Brazilian sun coffee plantations
}

\author{
Hugo Reis Medeiros ${ }^{1,2}$ (D) Yuri Campanholo Grandinete ${ }^{3}$ Paul Manning ${ }^{4} \cdot$ Karen A. Harper ${ }^{5,6}$. \\ G. Christopher Cutler ${ }^{4} \cdot$ Peter Tyedmers $^{6}$. Ciro Abbud Righi ${ }^{2,7} \cdot$ Milton Cezar Ribeiro ${ }^{1}$
}

Accepted: 14 October 2019 / Published online: 6 November 2019

(C) The Author(s) 2019

\begin{abstract}
Landscape structure and crop management directly affect insect communities, which can influence agriculturally relevant ecosystem services and disservices. However, little is known about the effect of landscape structure and local factors on pests, natural enemies, and biological control services in the Neotropics. We investigated how environmental conditions at local and landscape levels affect Leucoptera coffeella (insect pest), social wasps (natural enemies), and the provision of biological control services in 16 Brazilian coffee plantations under different crop management and landscape contexts. We considered microclimatic conditions, coffee plantation size, and management intensity at the local level; and forest cover, landscape diversity, and edge density at the landscape level. Pest population, wasp communities, and biocontrol services were monitored in wet and dry seasons when L. coffeella outbreaks occur. We found that the amount of forest in the surrounding landscape was more important for explaining patterns than the local environment, landscape diversity, or landscape configuration. In both seasons, L. coffeella was negatively affected by forest cover, whereas biological control and richness and abundance of social wasps increased with increasing forest cover at multiple spatial scales. Moreover, biological control was positively correlated with wasp abundance during pest outbreaks, suggesting that social wasps are important natural enemies and provide pest control services within coffee plantations. We provide the first empirical evidence that forest cover is important for the maintenance of social wasp diversity and associated pest control services in a Brazilian coffee-producing region.
\end{abstract}

Keywords Agroecosystems $\cdot$ Biodiversity conservation $\cdot$ Coffee leaf miner $\cdot$ Ecosystem services $\cdot$ Landscape structure $\cdot$ Social wasps

\section{Introduction}

Insects provide ecosystem services and disservices in agricultural landscapes with important environmental and

Hugo Reis Medeiros

hugo.medeiros.r@gmail.com

1 Instituto de Biociências, Departamento de Ecologia, Spatial Ecology and Conservation Lab (LEEC), UNESP - Universidade Estadual Paulista, Rio Claro, São Paulo 13506-900, Brazil

2 Programa de Pós-Graduação em Ecologia Aplicada (Interunidades), CENA - Centro de Energia Nuclear na Agricultura, Universidade de São Paulo, Piracicaba, São Paulo 13400-000, Brazil

3 Instituto de Biociências, Letras e Ciências Exatas (IBILCE), Departamento de Zoologia e Botânica, UNESP - Universidade Estadual Paulista, São José do Rio Preto, São Paulo 15054-000, Brazil socioeconomic consequences. Insect pests cause economic losses for farmers both directly by damaging cultivated plants, which reduces yield or quality, and indirectly by increasing production costs through the use of agrochemical inputs

4 Department of Plant, Food and Environmental Sciences, Faculty of Agriculture, Dalhousie University, Truro, Nova Scotia B2N 5E3, Canada Biology Department, Saint Mary's University, Halifax, Nova Scotia B3H 3C3, Canada

6 School for Resource and Environmental Studies and College of Sustainability, Dalhousie University, Halifax, Nova Scotia B3H 4R2, Canada

7 Departamento de Ciências Florestais, ESALQ/USP - Escola Superior de Agricultura "Luiz de Queiroz", Universidade de São Paulo, Piracicaba, São Paulo 13418-900, Brazil 
(Oerke 2006). It is estimated that in Brazil, annual pre-harvest losses from insect damage, the purchase of pesticides, and medical treatment for humans poisoned by insecticides reached US\$17.7 billion (Oliveira et al. 2014). However, ecosystem services provided by insects (e.g., pollination and pest control) have significant economic benefits and may compensate for these losses (Losey and Vaughan 2006).

Landscape structure and crop management directly affect the abundance and diversity of insect communities and associated ecosystem services and disservices (Tscharntke et al. 2012). Wild beneficial insects, such as pollinators and natural enemies, typically move into agricultural fields to exploit resources that are limited in time and space. These insects strongly depend on the presence of non-crop habitats to persist in agricultural landscapes (Tscharntke et al. 2012, 2016). Intensive use of pesticides in farms enhances mortality rates and sublethal effects in non-target beneficial insects (Geiger et al. 2010). In contrast, non-crop habitats (e.g., forest, grassland, wetland, hedgerows) that are less subject to pesticide applications experience relatively low rates of disturbance and provide a more reliable supply of food and shelter (Bianchi et al. 2006). These habitats are especially important when resources are not available in the crop matrix (e.g., fallow) or during disturbances such as pesticide applications, tilling, and harvest operations (Tscharntke et al. 2012). Complex landscapes with a large proportion of non-crop habitats provide spatiotemporal insurance for natural enemies and enhance the provision of pest control services into crop fields (Bianchi et al. 2006; Tscharntke et al. 2012). Although natural enemies seem to benefit more than pests from the presence of non-crop habitats, a number of pest species can also benefit from the presence of non-crop habitats (Tscharntke et al. 2016). Therefore, the importance of non-crop habitats as a source of natural enemies and biological control in farmland can vary according to pest biology, crop management, and landscape structure (Tscharntke et al. 2016).

The effects of landscape structure and crop management on insects and associated services and disservices have been widely investigated in temperate regions at multiple spatial scales. However, this relationship is understudied in Brazilian agricultural landscapes, where only a handful of recent studies have been reported (Sartuni et al. 2016; Librán-Embid et al. 2017; Hipólito et al. 2018; Aristizábal and Metzger 2018). Assessments in the Neotropics often rely on temperate data even though the effects of landscape elements and crop management on insects may differ between regions. Warm conditions in tropical regions associated with the overuse of pesticides allow crop production year-round - and most likely lead to more pest generations resulting in greater pest pressure due to the development of pest resistance to insecticides (Oliveira et al. 2014) and high mortality of natural enemies (Geiger et al. 2010). Moreover, the growing demand for agricultural land in the tropics and resulting intensive conversion of mega-diverse natural habitats into monocultures are leading to species loss and more pronounced effects of agricultural intensification on biodiversity and ecosystem services.

We studied the non-native but pervasive coffee leaf miner Leucoptera coffeella (Lepidoptera, Lyonetiidae) and native social wasps (Vespidae, Polistinae) as a model system. Leucoptera coffeella is a major coffee pest in Brazil (Pereira et al. 2007). A multivoltine insect, the larvae of $L$. coffeella are oligophagous and feed exclusively on species within the genus Coffea (Pierre 2011). This insect pest creates necrotic mines within the coffee leaf causing abscissions that reduce photosynthesis, productivity, and longevity of coffee plants (Pierre 2011). Social wasps are important natural enemies of lepidopteran crop pests including L. coffeella in coffee plantations (Ritcher 2000). In Brazil, Pereira et al. (2007) found that $49.5 \%$ of $L$. coffeella mortality in a coffee plantation was associated with predation by wasps. Predatory wasps forage and deliver important biocontrol services in agroecosystems, but most wasp species probably depend on the presence of non-crop habitats to find all required resources and nesting sites that are not available in farmland. In many Brazilian coffee-growing regions, coffee is produced in sun-grown plantations that are subject to frequent pesticide applications including organophosphates and pyrethroids that are highly toxic to non-target insects (Pereira et al. 2007). Moreover, most farmers remove wasp nests on their farms to avoid wasp stings during harvest. Despite its recognized importance, little is known about the effect of landscape structure and local variables on the diversity and abundance of social wasps as well as biological control services in Brazilian coffee plantations.

We investigated how environmental conditions at local and landscape levels affect the occurrence of the insect pest $L$. coffeella, social wasps, and the provision of biological control services in Brazilian coffee plantations during the wet season when the L. coffeella population is low, and during the dry season when outbreaks occur. We considered microclimatic conditions and agrochemical usage as factors at the local level, and forest cover, coffee cover, landscape diversity, and edge density as factors at the landscape level. We expected that forest is the key habitat for the maintenance of wasp diversity and associated biocontrol services and that landscapes with high forest cover support lower pest densities, more diverse wasp communities, and greater biological control services than landscapes dominated by monocultures.

\section{Material and methods}

\subsection{Study area}

The study was performed in 16 sun coffee plantations located in different crop management and landscape contexts near the 
border of the states of São Paulo and Minas Gerais in Southeast Brazil (Fig. 1a). This region produces approximately $25 \%$ of coffee in Brazil (Conab 2014) and is situated in the Atlantic Forest, a biome that supports high levels of biodiversity and endemism, but has been heavily fragmented (Myers et al. 2000). Atlantic Forest remnants in the study region are composed of secondary vegetation after experiencing intensive logging mainly in the 1970s and 1980s (local farmers, pers. comm.). These forest remnants are restricted to small and isolated fragments immersed in a matrix predominantly composed of sun coffee plantations with other land uses such as pasture, eucalyptus plantations, and sugar cane fields (LibránEmbid et al. 2017).

The study region encompasses mountainous relief in the north that becomes flatter in the south. Northern coffee is typically cultivated by small- and medium-scale producers without mechanization in hilly terrain at 850-1300 m.a.s.l. (Librán-Embid et al. 2017). In the south, coffee cultivation is dominated by medium- and large-scale producers who predominantly employ high levels of mechanization and cultivate coffee on level terrain at 700-850 m.a.s.l. Most farmers adopt conventional crop management incorporating fertilizers, insecticides, fungicides, and herbicides.

\subsection{Field surveys}

In each coffee plantation, we sampled social wasps (Vespidae, Polistinae) by using one malaise trap (Townes model; Fig. 1b) and three baited traps along a linear transect located at least $100 \mathrm{~m}$ away from the plantation edges with traps spaced $50 \mathrm{~m}$ apart. Baited traps (Fig. 1c) consisted of 2000-ml PET (polyethylene terephthalate) bottles hung from branches approximately $1.3 \mathrm{~m}$ above the ground with four circular holes of 4$\mathrm{cm}$-diameter cut midway and filled with $300 \mathrm{ml}$ of industrialized orange juice and $0.4 \mathrm{ml}$ of propylene glycol. Traps remained open for 7 consecutive days per month over 12 months from the dry season (June-November 2016) to the wet season (December-May 2017). Captured social wasps were preserved in $70 \%$ ethanol and identified to the lowest taxonomic level possible using identification keys. We estimated species richness $(S)$ and total abundance $(N)$ of wasps for each landscape and season, where $S$ and $N$ are the cumulative number of species and specimens recorded per coffee plantation, respectively. We obtained authorization from the Federal Government of Brazil to collect biological material during the entire period of this study (No. 54381-1, authentication code no. 87478664 Sisbio/IBAMA).

Within each coffee plantation, we visually assessed 200 coffee leaves per month over 12 months to estimate the number of mined leaves (pest abundance) and preyed mines (biological control) during the dry season from June to November 2016 (peak months of L. coffeella infestation, Librán-Embid et al. 2017) and the wet season from December 2016 to May 2017. Each month we randomly selected 10 coffee plants in the center of each plantation ( $>100 \mathrm{~m}$ from any edge) and 10 coffee plants along the edge of each plantation. We randomly selected five branches on each coffee plant and visually assessed the third pair of leaves from the branch tip $(n=10$ leaves per tree). The total number of mined coffee leaves and preyed mines per plantation was recorded on a monthly basis and used to estimate the proportion of mined leaves (pest abundance) and preyed mines (biological control) concurrent with the social wasp survey. We only considered leaves with fresh mines (dark brown in color) to estimate pest abundance. Predated mines can be readily differentiated from those in which $L$. coffeella larvae have completed development because mines attacked by predatory insects have characteristic linear cuts on the mine surface. In contrast, mines in which pest development is complete have a circular emergence opening at the margin of the mine (Pierre 2011). After assessment,
Fig. 1 a Typical sun coffeeproducing landscape in the study region. b Malaise trap. c Baited trap used to capture social wasps
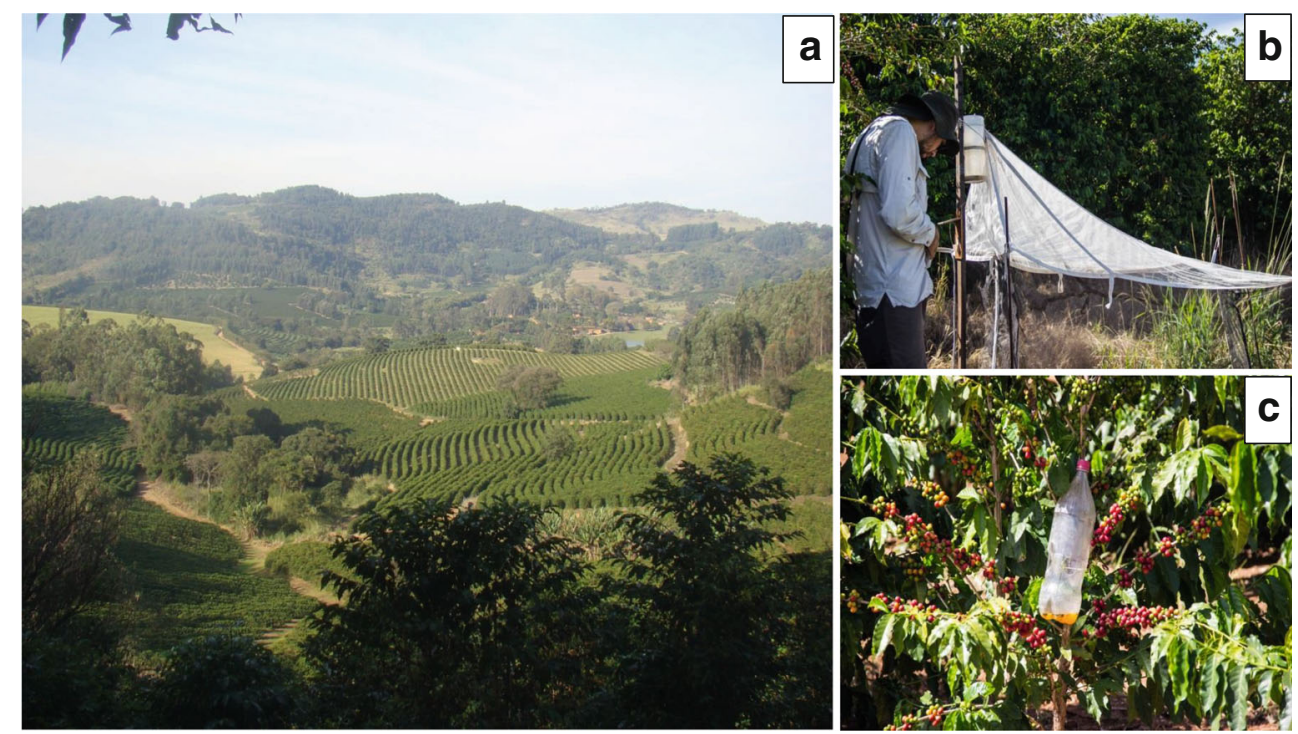
we marked each coffee plant using colored plastic ribbons to avoid evaluating the same tree twice.

\subsection{Local- and landscape-level variables}

We used agrochemical usage (total number of fertilizer, insecticide, herbicide, and fungicide applications) and microclimatic conditions (mean of temperature, humidity, and luminosity) within coffee plantations as explanatory variables related to local factors. We used Instrutherm ${ }^{\circledR}$ (model HT-500) data loggers to monitor temperature and humidity and HOBO Pendant ${ }^{\circledR}$ (model UA-002-64) data loggers to record luminosity. In each coffee plantation, both data loggers were attached to the malaise trap $1.3 \mathrm{~m}$ above the ground so that microclimate conditions were recorded every hour during insect surveys ( 7 days/month over 12 months). The number of fertilizer and pesticide applications in each coffee plantation was obtained by interviews with farmers.

To define the extent of our landscape, we considered the dispersal of social wasps. Little is known about their dispersal capacity in the Neotropics; however, some social wasp species in this region have a dispersal range of up to $300 \mathrm{~m}$ (da Cruz et al. 2006; Ribeiro-Filho et al. 2008). Based on this estimated range, we built land use maps at four scales from 250 to 1000 $\mathrm{m}$ radii using intervals of $250 \mathrm{~m}$. Maps were built using highresolution images from ArcGIS basemap imagery, 2013-2015 DigitalGlobe satellites, $0.5-1.0-\mathrm{m}^{2}$ resolution, and a 1:5000 visual scale. Extensive ground verification was used to

Table 1 List of competing models used to identify the most relevant variables to explain patterns of pests, natural enemies, and pest control services within coffee plantations in dry and wet seasons in Southeast Brazil

\begin{tabular}{ll}
\hline Model & Fixed effects \\
\hline Forest amount & $y \sim$ forest cover \\
Landscape diversity & $y \sim$ Shannon landscape diversity \\
Edge density & $y \sim$ edge density index \\
Fertilizer & $y \sim$ number of fertilizer applications \\
Insecticide & $y \sim$ number of insecticide applications \\
Herbicide & $y \sim$ number of herbicide applications \\
Fungicide & $y \sim$ number of fungicide applications \\
Temperature & $y \sim$ average temperature \\
Humidity & $y \sim$ average humidity \\
Luminosity & $y \sim$ average luminosity \\
Null & $y \sim 1$ \\
Pest abundance* & $y \sim L$. coffeella abundance \\
Wasp richness** & $y \sim$ number of species \\
Wasp abundance** & $y \sim$ number of individuals
\end{tabular}

*Included only in the list of competing models used to explain social wasp richness and abundance

**Used to explain biological control services achieve a high level of map accuracy. We used forest cover, coffee cover, landscape diversity, and edge density as landscape explanatory variables. We measured these variables within the radii of $250,500,750$, and $1000 \mathrm{~m}$ around the center of each sampled coffee plantation using ArcGIS 10.3.

Table 2 List of social wasp species (Vespidae: Polistinae) recorded in 16 coffee-producing landscapes in Southeast Brazil

\begin{tabular}{|c|c|}
\hline Species & Number of individuals \\
\hline Agelaia angulata (Fabricius, 1804) & 3 \\
\hline Agelaia multipicta (Haliday, 1836) & 1245 \\
\hline Agelaia pallipes (Olivier, 1792) & 852 \\
\hline Agelaia vicina (de Saussure, 1854) & 1196 \\
\hline Apoica pallens (Fabricius, 1804) & 67 \\
\hline Brachygastra augusti (de Saussure, 1854) & 1 \\
\hline Brachygastra lecheguana (Latreille, 1824) & 85 \\
\hline Brachygastra mouleae Richards, 1978 & 1 \\
\hline Metapolybia cingulata (Fabricius, 1804) & 1 \\
\hline Mischocyttarus cassununga (von Ihering, 1903) & 8 \\
\hline Mischocyttarus cearensis Richards, 1978 & 1 \\
\hline Mischocyttarus drewseni de Saussure, 1857 & 18 \\
\hline Mischocyttarus rotundicollis (Cameron, 1912) & 29 \\
\hline Mischocyttarus socialis (de Saussure, 1854) & 6 \\
\hline Mischocyttarus sp1 & 2 \\
\hline Polistes billardieri Fabricius, 1804 & 1 \\
\hline Polistes cinerascens de Saussure, 1854 & 2 \\
\hline Polistes erythrocephalus Latreille, 1813 & 31 \\
\hline Polistes lanio (Fabricius, 1775) & 4 \\
\hline Polistes melanosoma de Saussure, 1853 & 1 \\
\hline Polistes pacificus Fabricius, 1804 & 4 \\
\hline Polistes simillimus Zikán, 1851 & 38 \\
\hline Polistes sp1 & 1 \\
\hline Polistes subsericeus de Saussure, 1854 & 3 \\
\hline Polistes versicolor (Olivier, 1792) & 112 \\
\hline Polybia bifasciata de Saussure, 1854 & 4 \\
\hline Polybia chrysothotax (Lichtenstein, 1796) & 54 \\
\hline Polybia dimidiata (Olivier, 1792) & 9 \\
\hline Polybia fastidiosuscula de Saussure, 1854 & 414 \\
\hline Polybia ignobilis (Haliday, 1836) & 274 \\
\hline Polybia jurinei de Saussure, 1854 & 64 \\
\hline Polybia minarum Ducke, 1906 & 26 \\
\hline Polybia occidentalis (Olivier, 1792) & 393 \\
\hline Polybia paulista von Ihering, 1896 & 733 \\
\hline Polybia punctate du Buysson, 1908 & 130 \\
\hline Polybia sericea (Olivier, 1792) & 146 \\
\hline Protonectarina sylveirae (de Saussure, 1854) & 97 \\
\hline Protopolybia exigua (de Saussure, 1854) & 4 \\
\hline Protopolybia sedula (de Saussure, 1854) & 15 \\
\hline Pseudopolybia vespiceps (de Saussure, 1863) & 4 \\
\hline Synoeca cyanea (Fabricius, 1775) & 7 \\
\hline
\end{tabular}



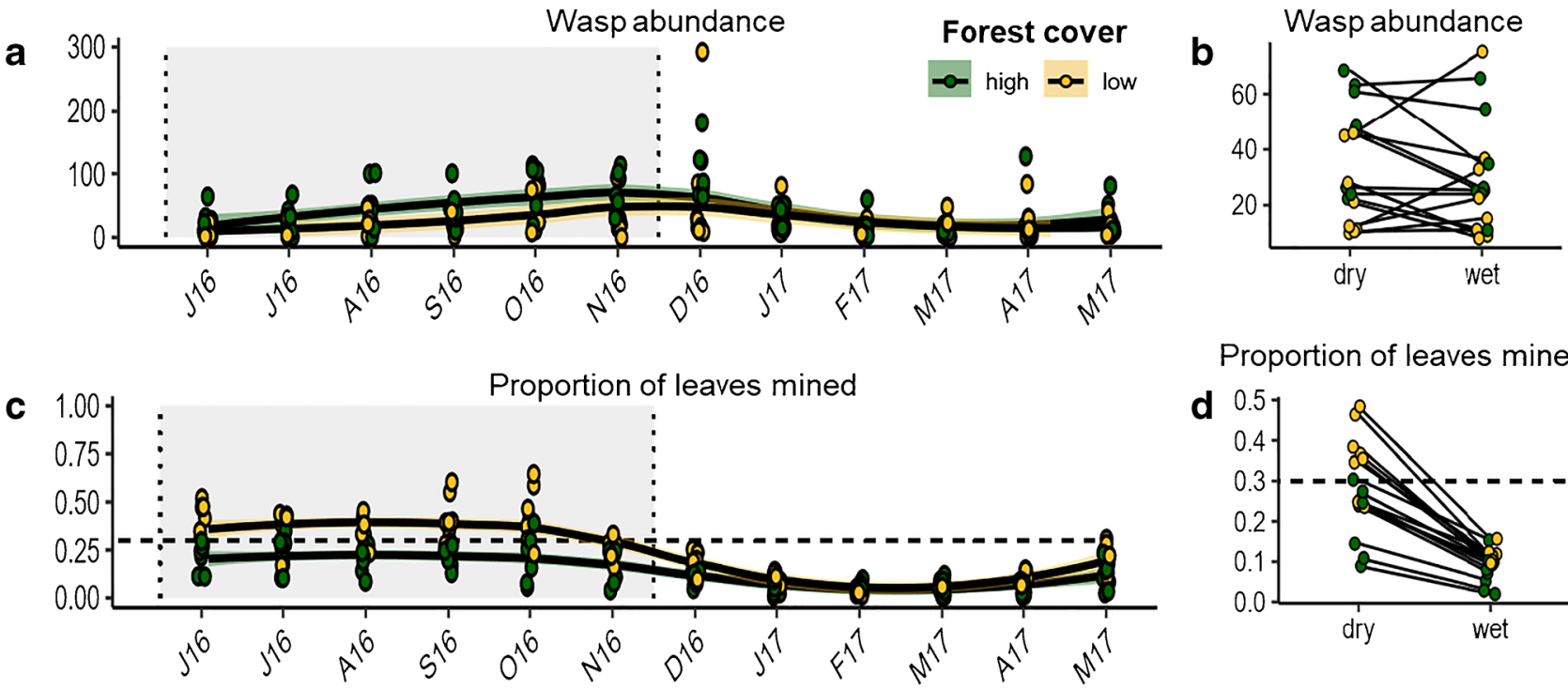

Proportion of leaves mined
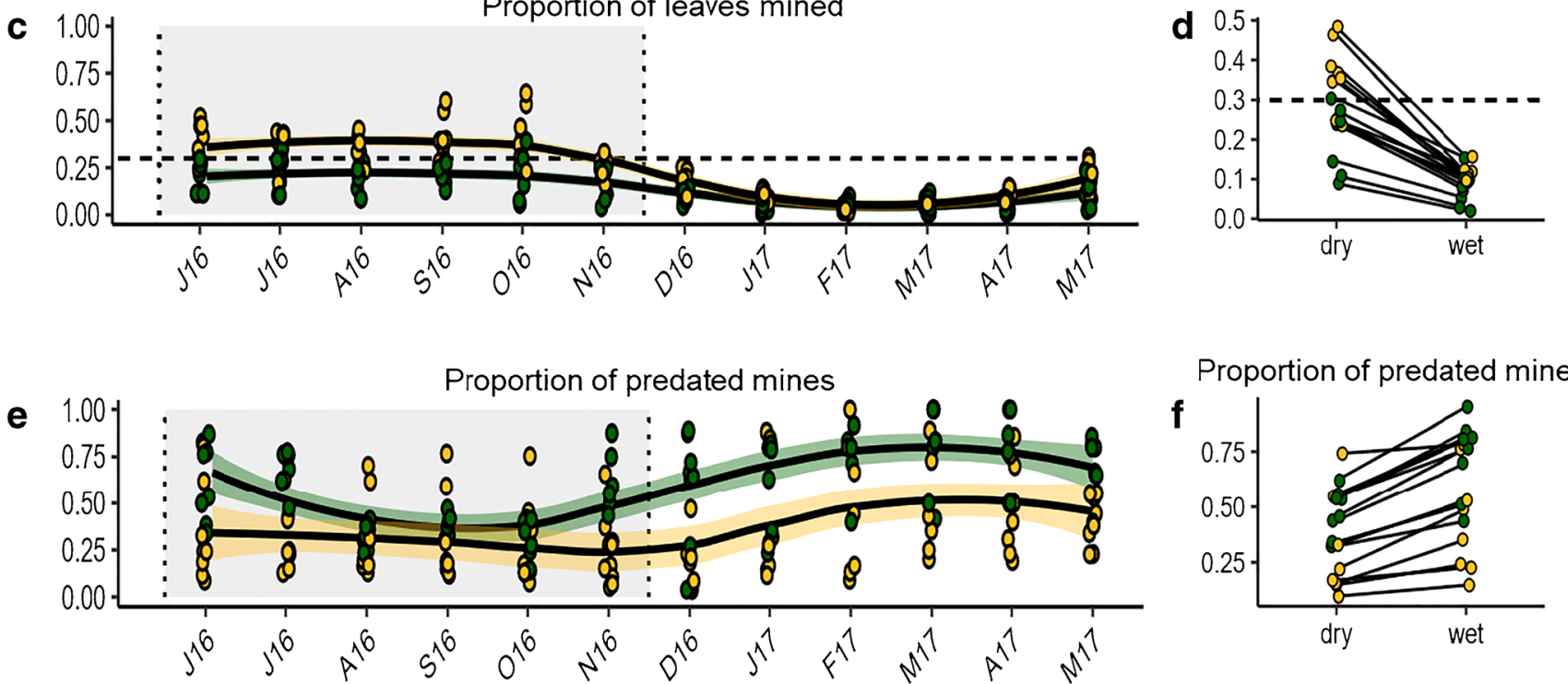

Fig. 2 Visualization of wasp abundance (a), proportion of mined leaves (L. coffeella abundance) (c), and proportion of preyed mines (biological control) (e) over 12 months from June 2016 (J16) to May 2017 (M17); and cumulative wasp abundance (b), L. coffeella abundance (d), and

Landscape diversity, which increases with an increasing number of habitat types in the landscape, was calculated using the Shannon diversity index, which considers both the number of land use classes and proportional area of each land use type (McGarigal 2015). Edge density represents the area of all land use patches in the landscape divided by the square of the nearest edge-to-edge distance between the focal patch and all land use types located within a pre-determined distance from the focal patch (McGarigal 2015). Coffee cover and forest cover were negatively correlated (absolute Spearman's correlations rs $>0.60 ; P<0.01$ ); thus, we excluded coffee cover from analyses to avoid multicollinearity.

\subsection{Statistical analyses}

We used generalized linear models to estimate the effects of local- and landscape-level variables on species richness and abundance of social wasps, which were fitted with the Poisson error structure. To estimate how local factors, landscape variables, and social wasp communities affect the proportion of mined leaves ( $L$. coffeella abundance) and proportion of biological control (f) in dry and wet seasons. Each point represents a measure taken from one of the 16 coffee plantations. In a, $\mathbf{c}$, and $\mathbf{e}$, the dry season is shaded in gray. The economic threshold of $30 \%$ coffee leaves mined is depicted as a dashed horizontal line in $\mathbf{c}$ and $\mathbf{d}$

preyed mines (biological control services), we used beta regressions, which are useful for models where the dependent variable is a continuous rate or proportion restricted to the standard unit interval $(0,1)$ (Cribari-Neto and Zeileis, 2010). For each dependent variable, spatial scale (i.e., buffer radius), and season (dry or wet), we analyzed 12 competing univariable models and a null model, which represented the absence of effects (Table 1).

The best models were identified using the Akaike information criterion (AIC; Burnham and Anderson 2002) with corrections for small samples. We used AICc weight (wAICc) and AICc delta $(\triangle \mathrm{AICc})$ to rank the models. The wAICc represents the weight of evidence in favor of a given model among competing models (Burnham and Anderson 2002). The $\triangle \mathrm{AICc}$ is the difference between the AICc of a considered model and the best model, i.e., the model with the lowest AICc value (Burnham and Anderson 2002). Models with significant model fit $(P$ values $<0.05)$, wAICc $\geq 0.1$, and $\Delta$ AICc $\leq 2.5$ ) were considered equally plausible at explaining the dependent variables (Medeiros et al. 2018). All analyses were performed in $\mathrm{R}$ version 3.5.2. We used the betareg function of the "betareg" package (Cribari-Neto and Zeileis, 2010) to fit 
Table 3 Significant models to explain the species richness and abundance of social wasps, pest occurrence, and natural pest control in 16 coffee-producing landscapes in Southern Brazil in the dry and wet seasons. wAICc $=$ evidence weight of the model. All selected models

\begin{tabular}{|c|c|c|c|c|c|c|}
\hline \multirow[t]{2}{*}{ Response variable } & \multirow[t]{2}{*}{ Season } & \multirow[t]{2}{*}{ Model } & \multicolumn{4}{|c|}{ wAICc at different spatial scales (m) } \\
\hline & & & 250 & 500 & 750 & 1000 \\
\hline \multirow[t]{2}{*}{ Wasp richness } & Dry & Forest cover $(+)$ & $0.998 * * *$ & $0.999 * * *$ & $0.995 * * *$ & $0.997 * * *$ \\
\hline & Wet & Forest cover $(+)$ & $0.665 * *$ & $0.625 * *$ & $0.590 * *$ & $0.615^{* *}$ \\
\hline \multirow[t]{2}{*}{ Wasp abundance } & Dry & Forest cover $(+)$ & $0.997 * * *$ & $0.999 * * *$ & $0.996 * * *$ & $0.995 * * *$ \\
\hline & Wet & Forest cover $(+)$ & $0.999 *$ & $0.995 *$ & - & - \\
\hline \multirow[t]{2}{*}{ L. coffeella } & Dry & Forest cover (-) & $0.870 * * *$ & $0.990 * * *$ & $0.902 * * *$ & $0.806^{* * *}$ \\
\hline & Wet & Temperature (+) & $0.535 * *$ & $0.563 * *$ & $0.517 * *$ & $0.560 * *$ \\
\hline \multirow[t]{3}{*}{ Biological control } & Dry & Forest cover $(+)$ & $0.759 * * *$ & $0.355 * * *$ & $0.383 * * *$ & $0.413^{* * *}$ \\
\hline & & Wasp abundance (+) & - & $0.373 * * *$ & $0.357 * * *$ & $0.340 * * *$ \\
\hline & Wet & Forest cover $(+)$ & $0.921 * * *$ & $0.781 * * *$ & $0.916^{* * *}$ & $0.882 * * *$ \\
\hline
\end{tabular}

$* P<0.05$

$* * P<0.01$

$* * * P<0.001$

beta regression models, and the AICctab function of the bbmle package (Bolker 2010) for model selection.

\section{Results and discussion}

Local and landscape explanatory variables varied considerably among the 16 landscapes. There were $2-13$ agrochemical applications (fertilizer, $0-3$; herbicide, $0-4$; fungicide, $0-4$; insecticide, $0-3)$ per coffee plantation during the year. Forest cover within the 1000-m buffer varied from 3 to $60 \%$, landscape diversity from 1.05 to 1.86 , and edge density from 127 to 246 .

We collected a total of 6086 social wasps (Vespidae, Polistinae), representing 42 species distributed across 11 genera (Table 2). The most abundant wasp species in both seasons were Agelaia multipicta ( $n=1245,20.5 \%$ of all specimens) and Agelaia vicina $(n=1197,19.7 \%)$. We collected 39 species and 3234 specimens of social wasps during the dry season, and 33 species and 2852 specimens during the wet season. Wasp species richness in dry and wet seasons was 9-29 and 9-21 species per landscape, respectively. Wasp abundance varied from 56 to 406 specimens during the dry season and from 49 to 458 specimens during the wet season (Fig. 2a, b). Species richness and abundance of social wasps were exclusively and positively associated with forest cover at multiple spatial scales (dry season wAICc $\geq$ 0.650, wet season wAICc $\geq 0.463$; Table 3 and Fig. 3a, b).

The habitat amount hypothesis suggests that species richness increases with increasing amount of habitat in the surrounding landscape independent of patch size and isolation (Fahrig 2013). This hypothesis seems to be true for social wasps in our study, which were positively correlated with forest cover irrespective of had $\triangle \mathrm{AICc}<2.0$. The symbols - and + within parentheses indicate the direction of correlation between response variables and fixed effects at four spatial scales $(250,500,750$, and $1000 \mathrm{~m})$
wAICc at different spatial scales (m) landscape diversity and edge density as well as local factors such as microclimate and management intensity. Social wasps are central foragers and need to move continually between nesting and feeding habitats (Richter 2000). Wasps use odor or visual cues such as leaf damage to find prey, and benefit from high densities of Lepidoptera pests in several agroecosystems, including L. coffeella in Brazilian coffee plantations (Richter 2000; Pereira et al. 2007). Therefore, social wasps search for prey within coffee plantations (feeding habitats) but build their nests in forest remnants (Oliveira et al. 2017). Intensive management (e.g., pesticide applications, pruning, and harvest) in many coffee plantations results in high mortality rates of wasps and destruction of their nests within coffee plantations. Wasp nests found in close proximity to humans (either within crops or on human-built structures) are usually removed to prevent wasp stings. Moreover, coffee monocultures have a short mass flowering period, and frequent applications of herbicides prevent establishment of ruderal plants that provide floral resources and alternative prey for wasps. In contrast, forest remnants provide undisturbed nesting habitats and a constant supply of floral resources, prey, and fiber for building nests when these resources are not available in coffee plantations. Social wasps did not respond to pesticide usage, suggesting that wasp communities inside forest remnants may serve as a permanent reservoir for wasps found in adjacent coffee plantations, allowing rapid recolonization of crops after disturbance such as pesticide applications and nest removal by farmers. Indeed, monocultures often fail to provide a constant supply of resources for beneficial insects, leading biological control agents to rely heavily on adjacent non-crop habitats to obtain their ecological needs and recolonize adjacent crop matrix after disturbances (Heimoana et al. 2017). 
Fig. 3 Best models and spatial scales to explain wasp abundance (a) and richness (b), L. coffeella abundance (c, d), and biological control (e,f) within 16 coffee plantations in southeastern Brazil during the dry season (June to November 2016) with the exception of the relationship between pest abundance and average temperature in the wet season for $\mathbf{c}$. The responses of wasp richness and abundance, $L$. coffeella abundance, and biological control were similar across spatial scales in both climatic seasons. Numbers in parentheses represent spatial scales of effect in meters/radius. The best models and spatial scales were selected based on the highest evidence weight (wAICc) of the models (Table 2)
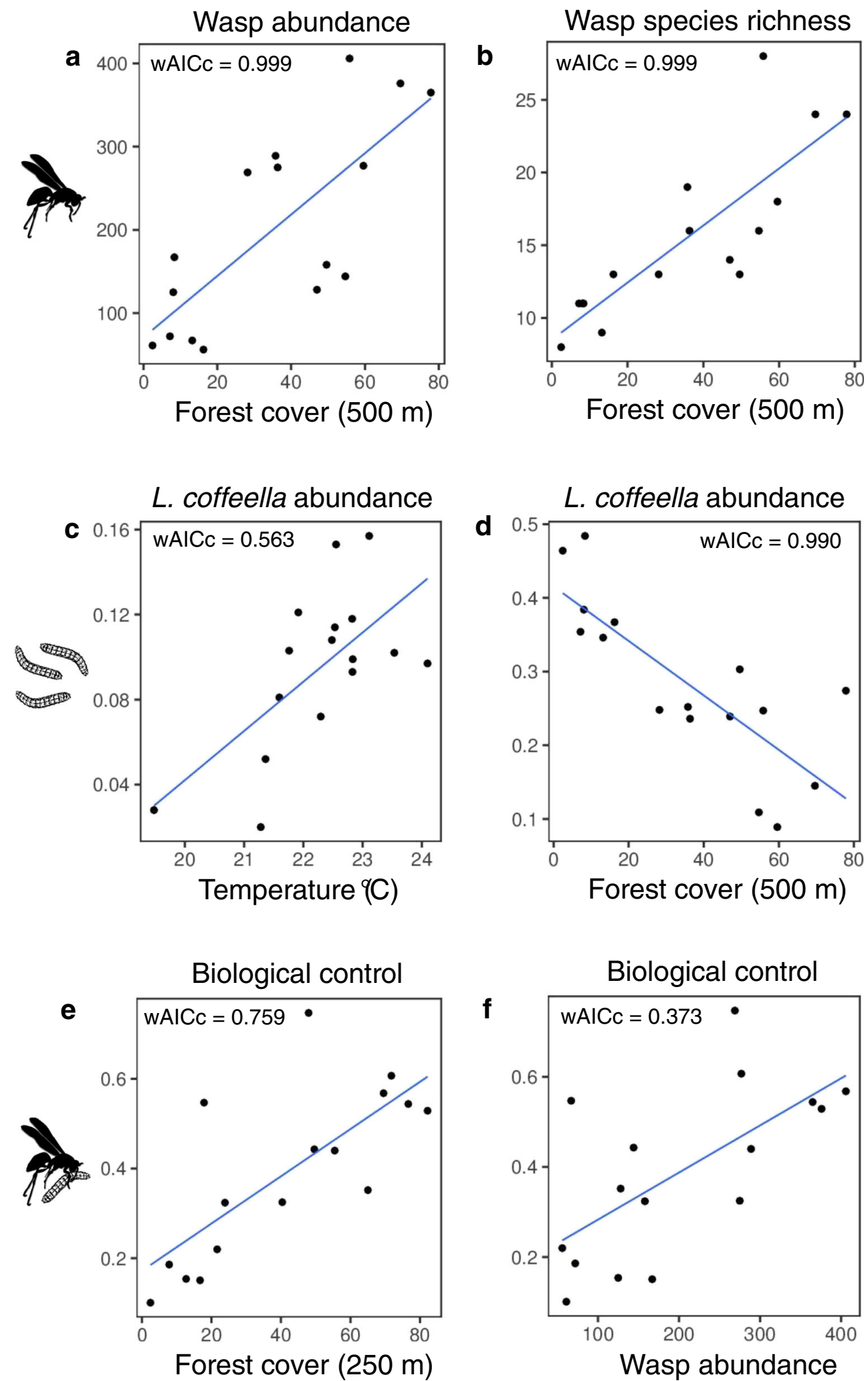

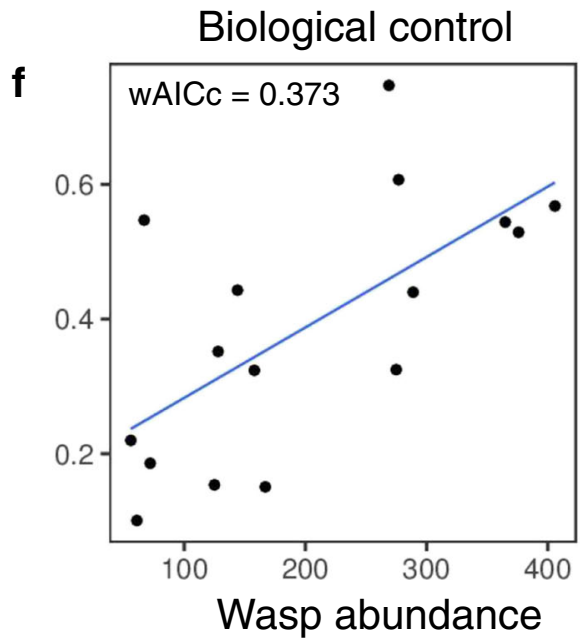

The number of mined leaves (L. coffeella abundance) varied considerably among the 16 landscapes and between seasons. There were 10-51\% mined leaves during the dry season, which surpassed the economic threshold of $30 \%$ of mined leaves (Reis et al. 2006) in seven coffee plantations (Fig. $2 \mathrm{c}, \mathrm{d})$. In the wet season, L. coffeella abundance generally declined, and only $2-16 \%$ of leaves were mined (Fig. 2c, d). The proportion of mined leaves decreased with increasing 
forest cover at all spatial scales in the dry season (wAICc $\geq$ 0.806; Table 3 and Fig. 3d) and increased with increasing temperature in the wet season (wAICc $\geq 0.517$; Table 3 and Fig. 3c). High forest cover means low cover of coffee, which is the only locally available host plant for this oligophagous leaf mining pest (Pierre 2011), thereby reducing recolonization potential between and within coffee plantations. Greater amounts of forest cover probably further reduce pest abundance by increasing natural enemy diversity and associated biological control services. Such generalized decline in $L$. coffeella abundance during the wet season can be associated with intense rainfall that is an important mortality factor of larvae (Pereira et al. 2007). Rainfall provokes the asphyxiation of larvae, and the positive response of $L$. coffeella to increasing temperature in the wet season can be associated with the fact that high temperatures enhance evaporation and can reduce water saturation in coffee leaves (Righi et al. 2013).

The proportion of preyed mines (biological control) ranged from 10 to $65 \%$ in the dry season and from 15 to $92 \%$ during the wet season (Fig. 2e, f). Biological control was positively associated with wasp abundance in the dry season (wAICc $\geq$ 0.340; Table 3 and Fig. 3e) and with forest cover at multiple spatial scales (dry season wAICc $\geq 0.355$, Fig $3 f$; and wet season wAICc $\geq 0.781$, Table 3 ). High forest cover promoted high levels of biological control even in the wet season when wasp abundance was not correlated with the proportion of preyed mines. These findings indicate that social wasps are important natural enemies of $L$. coffeella, but not exclusive since predation marks on leaf mines are also related to other predatory insects such as ants and carabid beetles. Moreover, we probably underestimated biological control services because we did not account for parasitism that is also an important mechanism of biological control of L. coffeella in Brazilian coffee plantations (Pierre 2011).

Generalist natural enemies such as predatory insects affect food web dynamics in natural and agroecosystems by foraging among different habitats to exploit different resources that are spatially separated in changing landscapes (Tscharntke et al. 2012). Social wasp diversity and biological control in coffee plantations were regulated by forest cover at the landscape scale, suggesting that predatory insects are highly mobile and can provide biocontrol services at larger spatial scales covering several coffee plantations. In fragmented landscapes in Brazil, at least 30-35\% forest cover is needed to maintain high levels of animal diversity, including birds, mammals, amphibians (Banks-Leite et al. 2014), and bees (Ferreira et al. 2015). Although some previous studies detected thresholds where biological responses hinged on the amount of forest cover, our variables of interest were always linearly correlated, meaning that with more forest, there was higher wasp diversity and better provision of biological control services.

\section{Conclusion}

We provide the first empirical evidence that the amount of forest cover on the landscape increases social wasp diversity and biological control of a widespread economic pest in a Brazilian coffee-producing region. Thus, we recommend that agri-environment schemes in tropical agricultural landscapes should focus on the conservation of forest remnants and forest restoration in areas of low agricultural importance, abandoned crops, and riparian areas at multiple spatial scales. Understanding the effects of non-crop habitats on insect communities and associated ecosystem services and disservices they support, is an essential part of achieving more sustainable agricultural systems. The importance of these forest patches as sources of ecosystem services will vary depending on the crop, service, nature and extent of non-agricultural land cover, and management practice (Tscharntke et al. 2016). Although the delivery of agriculturally relevant ecosystem services will not and should not be the primary argument for conserving and restoring forested habitat in the Neotropics, results of studies like ours show that in some cases, there can be direct benefits to agricultural production derived from forested land in the wider landscape. A better understanding of how landscape structure and crop management mediate trade-offs between ecosystem services and disservices is crucial to aid regional planners in selecting appropriate spatial and temporal scales and policies in decisionmaking.

Acknowledgments We are grateful to the owners of the private lands where study sites are located. We thank Danilo Boscolo, Felipe Martello, and Jean Paul Metzger who helped us to substantially improve the manuscript. YCG thanks Rogério Botion Lopes and Gustavo Bellini Cortes who collaborated in some species identifications and sorting of malaise material.

Funding information This study received financial support from the Rufford Foundation for field-work activities (reference project: 18799-1). This study was also supported by São Paulo Research Foundation (FAPESP) process no. 2013/50421-2. HRM received a research grant from the Brazilian Government Research Council (CNPq) (142147/2015-0/141932/2016-3) and a scholarship from the Emerging Leaders of Americas Program (ELAP) supported by the Canadian Government. PM is funded by an Isaac Walton Killam Postdoctoral Fellowship. KAH receives funding from the Natural Sciences and Engineering Research Council of Canada. MCR thanks São Paulo Research Foundation (FAPESP; process no. 2013/50421-2), CNPq (processes nos. 312045/2013-1; 312292/ 2016-3), and PROCAD/CAPES (project no. 88881.068425/201401 ) for their financial support.

\section{Compliance with ethical standard}

Conflict of interest The authors declare that they have no conflict of interest. 
Open Access This article is distributed under the terms of the Creative Commons Attribution 4.0 International License (http:// creativecommons.org/licenses/by/4.0/), which permits unrestricted use, distribution, and reproduction in any medium, provided you give appropriate credit to the original author(s) and the source, provide a link to the Creative Commons license, and indicate if changes were made.

\section{References}

Aristizábal N, Metzger JP (2018) Landscape structure regulates pest control provided by ants in sun coffee farms. J Appl Ecol 56:21-30. https://doi.org/10.1111/1365-2664.13283

Banks-Leite C, Pardini R, Tambosi LR, Pearse WD, Bueno AA, Bruscagin RT, Condez TH, Dixo M, Igari AT, Martensen AC, Metzger JP (2014) Using ecological thresholds to evaluate the costs and benefits of set-asides in a biodiversity hotspot. Science 345 : 1041-1045. https://doi.org/10.1126/science. 1255768

Bianchi FJJA, Booij CJH, Tscharntke T (2006) Sustainable pest regulation in agricultural landscapes: a review on landscape composition, biodiversity and natural pest control. Proc R Soc Lond B 273:17151727. https://doi.org/10.1098/rspb.2006.3530

Bolker BM (2010) bbmle: Tools for general maximum likelihood estimation. The Comprehensive R Archive Network (CRAN), Vienna

Burnham KP, Anderson DR (2002) Model selection and multimodel inference: a practical information-theoretical approach. SpringerVerlag, New York

Conab (2014) Café. Safra 2014. Terceiro Levantamento. http:// www.conab.gov.br/OlalaCMS/uploads/arquivos/ 14_09_16_08_47_43_boletim_setembro_2014.pdf. (accessed 13 July 2017).

Cribari-Neto F, Zeileis A (2010) Beta regression in R. J Stat Softw 32:124. https://doi.org/10.18637/jss.v034.i02

da Cruz JD, Giannotti E, Santos GMM, Bichara CC, da Rocha AA (2006) Nest site selection and flying capacity of neotropical wasp Angiopolybia pallens (Hymenoptera: Vespidae) in the Atlantic Rain Forest, Bahia state, Brazil. Sociobiology 47:739-749 http:// hdl.handle.net/11449/68916

Fahrig L (2013) Rethinking patch size and isolation effects: the habitat amount hypothesis. J Biogeogr 40:1649-1663. https://doi.org/10. 1111/jbi. 12130

Ferreira PA, Boscolo D, Carvalheiro LG, Biesmeijer JC, Rocha PL, Viana BF (2015) Responses of bees to habitat loss in fragmented landscapes of Brazilian Atlantic Rainforest. Landsc Ecol 30:20672078. https://doi.org/10.1007/s10980-015-0231-3

Geiger F, Bengtsson J, Berendse F et al (2010) Persistent negative effects of pesticides on biodiversity and biological control potential on European farmland. Basic Appl Ecol 11:97-105. https://doi.org/ 10.1016/j.baae.2009.12.001

Heimoana V, Pilkington LJ, Raman A, Mitchell A, Nicol HI, Johnson AC, Gurr GM (2017) Integrating spatially explicit molecular and ecological methods to explore the significance of non-crop vegetation to predators of brassica pests. Agric Ecosyst Environ 239:12 19. https://doi.org/10.1016/j.agee.2017.01.008

Hipólito J, Boscolo D, Viana BF (2018) Landscape and crop management strategies to conserve pollination services and increase yields in tropical coffee farms. Agric Ecosyst Environ 256:218-225. https:// doi.org/10.1016/j.agee.2017.09.038

Librán-Embid F, De Coster G, Metzger JP (2017) Effects of bird and bat exclusion on coffee pest control at multiple spatial scales. Landsc Ecol 32:1907-1920. https://doi.org/10.1007/s10980-017-0555-2
Losey JE, Vaughan M (2006) The economic value of ecological services provided by insects. BioScience:311-323. https://doi.org/10.1641/ 0006-3568(2006)56[311:TEVOES]2.0.CO;2

McGarigal K (2015) Fragstats help. http://www.umass.edu/landeco/ research/fragstats/documents/fragstats/ Accessed 03.05.15

Medeiros HR, Hoshino AT, Ribeiro MC, Morales MN, Martello F, Neto OCP, Carstensen DW, Menezes AO Jr (2018) Non-crop habitats modulate alpha and beta diversity of flower flies (Diptera, Syrphidae) in Brazilian agricultural landscapes. Biodivers Conserv 27:1309-1326. https://doi.org/10.1007/s10531-017-1495-5

Myers N, Mittermeier RA, Mittermeier CG, Da Fonseca GA, Kent J (2000) Biodiversity hotspots for conservation priorities. Nature 403:853-858 https://www.nature.com/articles/35002501

Oerke EC (2006) Crop losses to pests. J Agric Sci 144:31-43. https://doi. org/10.1017/S0021859605005708

Oliveira CM, Auad AM, Mendes SM, Frizzas MR (2014) Crop losses and the economic impact of insect pests on Brazilian agriculture. Crop Prot 56:50-54. https://doi.org/10.1016/j.cropro.2013.10.022

Oliveira TCT, Souza MM, Pires EP (2017) Nesting habits of social wasps (Hymenoptera: Vespidae) in forest fragments associated with anthropic areas in southeastern Brazil. Sociobiology 36:189-196. https://doi.org/10.13102/sociobiology.v64i1.1073

Pereira EJG, Picanço MC, Bacci L, Crespo ALB, Guedes RNC (2007) Seasonal mortality factors of the coffee leafminer, Leucoptera coffeella. Bull Entomol Res 97:421-432. https://doi.org/10.1017/ S0007485307005202

Pierre LSR (2011) Níveis populacionais de Leucoptera coffeella (Lepidoptera: Lyonetiidae) e Hypothenemus hampei (Coleoptera: Scolytidae) e a ocorrência de seus parasitoides em sistemas de produção de café orgânico e convencional. $\mathrm{PhD}$, Universidade de São Paulo.

Reis PR, Souza JC, Zacarias MS (2006) Alerta para o bicho-mineiro. Cultivar 8:13-16 https://www.researchgate.net/publication/ 285830375_Alerta_para_o_bicho-mineiro

Ribeiro-Filho C, Elisei T, Guimaraes DL, Prezoto F (2008) Flight range extension in the swarm-founding wasp Protopolybia exigua (Hymenoptera, Vespidae, Epiponini). Sociobiology 51(1):173-180

Richter MR (2000) Social wasp (Hymenoptera: Vespidae) foraging behavior. Annu Rev Entomol 45:121-150. https://doi.org/10.1146/ annurev.ento.45.1.121

Righi CA, Campoe OC, Bernardes MS, Lunz AMP, Piedade SMS, Pereira CR (2013) Influence of rubber trees on leaf-miner damage to coffee plants in an agroforestry system. Agroforest Syst. 87: 1351-1362. https://doi.org/10.1007/s10457-013-9642-9

Saturni FT, Jaffé R, Metzger JP (2016) Landscape structure influences bee community and coffee pollination at different spatial scales. Agric Ecosyst Environ 235:1-12. https://doi.org/10.1016/j.agee. 2016.10.008

Tscharntke T, Tylianakis JM, Rand TA et al (2012) Landscape moderation of biodiversity patterns and processes-eight hypotheses. Biol Rev 87:661-685. https://doi.org/10.1111/j.1469-185X.2011.00216. $\mathrm{x}$

Tscharntke T, Karp DS, Chaplin-Kramer R et al (2016) When natural habitat fails to enhance biological control - five hypotheses. Biol Conserv 204:449-458. https://doi.org/10.1016/j.biocon.2016.10. 001

Publisher's note Springer Nature remains neutral with regard to jurisdictional claims in published maps and institutional affiliations. 